\title{
Validation of the Zulfiqar Frailty Scale (ZFS): A New Tool for General Practitioners
}

\author{
Abrar-Ahmad Zulfiqar (1)
}

check for

updates

Citation: Zulfiqar, A.-A. Validation of the Zulfiqar Frailty Scale (ZFS): A New Tool for General Practitioners. Medicines 2021, 8, 52. https:// doi.org/10.3390/medicines 8090052

Academic Editor: Emmanuel Andrès

Received: 15 August 2021

Accepted: 2 September 2021

Published: 4 September 2021

Publisher's Note: MDPI stays neutral with regard to jurisdictional claims in published maps and institutional affiliations.

Copyright: (C) 2021 by the author. Licensee MDPI, Basel, Switzerland. This article is an open access article distributed under the terms and conditions of the Creative Commons Attribution (CC BY) license (https:// creativecommons.org/licenses/by/ $4.0 /)$.
Service de Médecine Interne, Diabète et Maladies Métaboliques de la Clinique Médicale B, Hôpitaux Universitaires de Strasbourg et Equipe EA 3072 "Mitochondrie, Stress Oxydant et Protection Musculaire", Faculté de Médecine-Université de Strasbourg, 67000 Strasbourg, France; abzulfiqar@gmail.com

\begin{abstract}
Introduction: The early detection of frailty, a frequent transient state that can be reversible in the elderly and is responsible for significant morbidity and mortality, helps prevent complications from it. Objective: To evaluate the performance of the "ZFS" tool to screen for frailty as defined SEGA scale criteria in an ambulatory population of patients at least 65 years of age. Methods: A prospective non-interventional study conducted in Alsace for a duration of six months that included patients aged 65 and over, judged to be autonomous with an ADL > 4/6. Results: In this ambulatory population of 102 patients with an average age of 76 years, frailty, according to modified SEGA criteria grid A, had a prevalence of $19.6 \%$. Frailty, according to the "ZFS" tool, had a prevalence of $35.0 \%$, and all of its elements except weight loss were significantly associated with frailty. Its threshold for identifying frailty is three criteria out of six. It was rapid (average completion time: 87 s), had a sensitivity of $100 \%$, and a negative predictive value of $100 \%$. Conclusions: The "ZFS" tool makes it possible to screen for frailty with a high level of sensitivity and a negative predictive value.
\end{abstract}

Keywords: ZULFIQAR Frailty Scale (ZFS); modified SEGA scale grid A; primary care; prevention; elderly subjects

\section{Introduction}

General practitioners, in their role of prevention and screening, are key players in detecting risky lifestyle habits. Nevertheless, frailty remains difficult to identify in primary care due to the multitude of definitions and existing diagnostic tools. Moreover, their use is not systematically adapted to the liberal mode of exercise.

Currently, no scale is valid to screen for frailty, just as there is no consensus definition. They all differ in the number and nature of their criteria assessed. Certain scales seem rather adapted to the hospital environment while others are intended primarily for the general practitioner. Table 1 describes some frailty scales (non-exhaustive list).

With the aim of harmonizing professional practices and making the identification of frailty in general medicine consultations accessible, we have proposed a frailty screening tool, the Zulfiqar Frailty Scale (ZFS). This scale is made up of six elements, which are specified in Table 2.

For scores of three or more, the elderly patient was considered by our scale to be "frail". For scores of one or two, the patient was considered "pre-frail". For a score of 0 , the patient was considered "non-frail" or "robust".

This tool brings together six elements which, in the literature, are significantly and independently associated with a poor prognosis in terms of morbidity and mortality and which therefore fall within the definition of a marker of frailty $[11,12]$.

- Nutritional status

- Balance and falls

- Cognitive function

- $\quad$ Level of sociability 


\section{- Polypharmacy}

This choice of elements was based on their rapid completion time as well as on their simplicity. As such, prior training was not required.

The originator study was conducted in a general practice in Brittany, France to validate our frailty scale, as published in the journal MEDICINES MDPI [9].

Table 1. Frailty scales (non-exhaustive list).

\begin{tabular}{|c|c|c|c|c|c|}
\hline Frailty Scale & Area Explored & Prevalence & Number of Items & Duration & Place of Realization \\
\hline Fried [1] & Sarcopenia & $11 \%$ & 5 & $10 \mathrm{~min}$ & Hospital ++ \\
\hline Frailty Index [2] & Multidimensional & $34 \%$ & 70 & $15 \mathrm{~min}$ & Hospital ++ \\
\hline $\begin{array}{l}\text { Short Emergency Geriatric } \\
\text { Assessment (SEGA) [3-5] }\end{array}$ & Multidimensional & $90 \%$ & 24 & $10 \mathrm{~min}$ & $\begin{array}{c}\text { Emergency Unit } \\
++/ \text { Hospital } \\
++/ \text { Primary care } \\
+/ \text { Home }+\end{array}$ \\
\hline $\begin{array}{c}\text { Gérontopôle Frailty Screening } \\
\text { Tool (GFST) [6-8] }\end{array}$ & $\begin{array}{l}\text { Multidimensional } \\
\text { Sarcopenia }\end{array}$ & $24.5 \%$ & $\begin{array}{c}6+1 \text { (General } \\
\text { Practitioners subjectivity) }\end{array}$ & $2 \mathrm{~min}$ & $\begin{array}{l}\text { Primary care }+++ \\
\text { Home }+++\end{array}$ \\
\hline Zulfiqar Frailty Scale (ZFS) $[9,10]$ & $\begin{array}{l}\text { Multidimensional } \\
\text { Sarcopenia }\end{array}$ & $63.7 \%$ & 5 & $2 \mathrm{~min}$ & $\begin{array}{c}\text { Primary care }+++ \\
\text { Home }+++\end{array}$ \\
\hline $\begin{array}{c}\text { Comprehensive Geriatric } \\
\text { Assessment (CGA) }\end{array}$ & $\begin{array}{l}\text { Multidimensional All } \\
\text { areas of geriatrics }\end{array}$ & - & $\begin{array}{l}\text { MNA, ADL, IADL, MMS, } \\
\text { TCH, miniGDS, Walk test, } \\
\text { Vision, Audition, } \\
\text { Polymedication, Social, } \\
\text { Financial status }\end{array}$ & More than one hour & Hospital +++++ \\
\hline
\end{tabular}

+: little used; ++: ofently used; +++: frequently used; +++++: exclusively used.

Table 2. Criteria of the Zulfiqar Frailty Scale $[9,10]$.

\section{Zulfiqar Frailty Scale (ZFS)}

Is there a weight loss greater than or equal to $5 \%$ in 6 months? Monopod support test $<5 \mathrm{~s}$ ?

Does the person live alone at home?

Are there home caregivers?

Does the person complain of memory problems?

Does the person have prescriptions for more than 5 therapeutic classes on his/her prescription history for less than 6 months?

$\begin{array}{ll}\text { Yes } & \text { No } \\ \text { Yes } & \text { No } \\ \text { Yes } & \text { No } \\ \text { Yes } & \text { No } \\ \text { Yes } & \text { No } \\ \text { Yes } & \text { No }\end{array}$

\section{Patients and Methods}

\subsection{Method}

To answer our research question, a prospective study was set up. The latter was conducted at three general medicine practices in the Haut-Rhin departments, specifically in Mulhouse (Saint-Louis) and Colmar (Alsace), for a total period of six months (from 2 November 2020 to 30 April 2021).

\subsection{Primary Objective}

The objective of the study was to validate the Zulfiqar Frailty Scale (ZFS) and to analyze its concordance with the modified SEGA scale (mSEGA) part A (Short Emergency Geriatric Assessment), rated out of 26 and comprising 13 elements (link can be found at https:/ / reseaux-sante-ca.org/IMG/pdf/grille_de_fragilite_volet_a-b_2014.pdf (accessed on 15 August 2021) [3-5].

We chose the modified SEGA frailty scale because the study took place in the Grand Est (France) where this scale is used, particularly with the RéGéCa network [3-5].

\subsection{Inclusion Criteria}

The patients needed to be 65 years of age or over, in consultation with a general practitioner, and with an ADL (Activity of Daily Living) greater than or equal to four. Patients less than 65 years old and subjects with an ADL less than four were excluded from 
this study. Those living in nursing homes were also excluded, as were patients unable to express themselves or give their consent.

\subsection{Data Collected and Analyzed}

Data for the study was recorded by the general practitioner during routine consultations. For each patient, the mSEGA frailty scale part A was carried out as well as the Zulfiqar Frailty Scale. The information was then anonymized before being transmitted for collection in the study.

\subsection{Statistical Analysis}

The statistics were produced using R 3.6.1 software. Qualitative variables were expressed by their numbers and percentages by the response method; quantitative variables were expressed as mean and standard deviation. A Pearson correlation matrix was used to study the correlations between elements and between the total scores of the two scales. In order to assess the properties of the Zulfiqar Frailty Scale, a comparison was made to the mSEGA scale part A with patients considered to be frail with a score of $>8 / 26$. As such, a ROC curve could be drawn, an area under the curve was calculated, and the optimal threshold was defined with sensitivity, specificity, positive and negative predictive values, and the Youden score.

\subsection{Administrative Elements}

Informed consent was obtained from all patients included in this study. From a regulatory standpoint, the study was registered with the CNIL (National Commission for Informatics and Liberties) according to the MR-004 reference methodology and with the Heath Data Hub directory. Internal Department Ethics Committee of University Hospital of Strasbourg approved this paper for publication (No. 18-10-20).

\section{Results}

\subsection{Description of the Population}

During this collection period, 102 patients over 65 years of age were included. We did not note any refusals. The characteristics of the population included are detailed in Table 3. Tables 4 and 5 specify the characteristics of the frailty scales used (the frailty scale known as Zulfiqar or ZFS (1) and a modified version of the mSEGA scale grid A).

Table 3. Description of the sample.

\begin{tabular}{cc}
\hline Population Characteristics (n = 102) & \\
\hline Age m (sd) & $76(8)$ \\
\hline Gender & \\
Female & $55(54 \%)$ \\
Male & $47(46 \%)$ \\
\hline Weight $(\mathrm{kgs}), \mathrm{m}(\mathrm{sd})$ & $74(15)$ \\
Height $(\mathrm{cm}), \mathrm{m}(\mathrm{sd})$ & $166(9)$ \\
Medical history (\%) & $70(68.6)$ \\
Cardiovascular & $11(10.7)$ \\
Pulmonary & $13(13)$ \\
Gastrointestinal & $25(24.5)$ \\
Endocrine & $14(14)$ \\
Neurological & $15(15)$ \\
Psychiatric & $26(25)$ \\
Obesity & $17(17)$ \\
Oncological &
\end{tabular}


Table 3. Cont.

\begin{tabular}{cc}
\hline \multicolumn{2}{c}{ Population Characteristics $(\mathbf{n}=\mathbf{1 0 2})$} \\
\hline $\begin{array}{c}\text { Medication, } \mathrm{m}(\mathrm{sd}) \\
\text { Charlson score (comorbidities score), } \mathrm{m}(\mathrm{sd})\end{array}$ \\
\hline Hospitalization in the last 6 months & $4.3(3.0)$ \\
Yes & $4.11(1.81)$ \\
No & $10(9.8 \%)$ \\
\hline Fall in the last 6 months & $92(90.2 \%)$ \\
Yes & $17(17 \%)$ \\
No & $85(83 \%)$ \\
\hline ADL $(/ 6), \mathrm{m}(\mathrm{sd})$ & $5.83(0.35)$ \\
\hline IADL $(/ 4), \mathrm{m}(\mathrm{sd})$ & $7.04(1.68)$ \\
\hline
\end{tabular}

ADL: Activity Daily Living; IADL: Instrumental Activity Daily Living.

Table 4. Zulfiqar Frailty Scale (ZFS).

\section{Zulfiqar Frailty Scale (ZFS)}

\begin{tabular}{|c|c|}
\hline \multicolumn{2}{|l|}{ Zulfiqar Frailty Scale (ZFS) } \\
\hline & Population Included $(\mathrm{n}=102)$ \\
\hline Zulfiqar Frailty Scale (ZFS) & Yes \\
\hline Does the person live alone at home? & $45(44)$ \\
\hline Are there home caregivers? & $25(24.5)$ \\
\hline Is there a weight loss greater than or equal to $5 \%$ in 6 months? & $6(5.9)$ \\
\hline Monopod support test $<5 \mathrm{~s}$ ? & $55(54)$ \\
\hline Does the person complain of memory problems? & $35(34)$ \\
\hline $\begin{array}{c}\text { Does the person have prescriptions for more than } 5 \text { therapeutic classes on his/her } \\
\text { prescription history for less than } 6 \text { months? }\end{array}$ & $46(45)$ \\
\hline ZFS, m (sd) & $2.1(1.35)$ \\
\hline Duration time, $\mathrm{m}$ & $87(72-108)$ \\
\hline \multicolumn{2}{|l|}{ Classification } \\
\hline Not frail & $15(15)$ \\
\hline Pre-frail & $51(50)$ \\
\hline Frail & $36(35)$ \\
\hline \multicolumn{2}{|l|}{ Frailty according to ZFS } \\
\hline No & $15(15)$ \\
\hline Yes & $87(87)$ \\
\hline
\end{tabular}

Table 5. mSEGA scale grid A.

\begin{tabular}{cc}
\hline mSEGA Scale Grid A & \\
\hline mSEGA, m (sd) & $5.61(3.11)$ \\
\hline Classification & $4(4)$ \\
Very frail $(>11)$ & $82(80)$ \\
Not frail $(<=8)$ & $16(16)$ \\
Frail (9-11)
\end{tabular}

\subsection{Correlation between the SEGA and Zulfigar Frailty Scales}

Pearson's correlation coefficient (or Pearson's r) and its 95\% confidence interval was $0.81[0.73 ; 0.86]$. Table 6 presents the Pearson correlation matrix between the elements of the mSEGA grid A and Zulfiqar Frailty Scale (ZFS).

\subsection{Performance and Validity of the Zulfigar Frailty Scale}

Table 7 presents a comparison of the element scores of the Zulfiqar Frailty Scale between frail and non-frail patients. 
All results evaluating our screening tool against the SEGA criteria are shown in Table 8.

- Weight loss

"Weight loss of at least $5 \%$ of body weight over the past six months" had a sensitivity of $20 \%$ and a specificity of $98 \%$. Its negative predictive value was $83 \%$, and its positive predictive value was $67 \%$.

Patients responding positively to this element had a four-fold risk of being frail.

- Monopodal balance

To identify frailty, the sensitivity of the "Monopodal balance less than $5 \mathrm{~s}$ " element was $85 \%$, and the specificity was $54 \%$. Its negative predictive value was $94 \%$, and the positive predictive value was $31 \%$.

Patients with abnormal monopodal balance were 4.84 times more likely to be frail.

- $\quad$ Lives alone

The sensitivity of the "Living alone at home" element was 65\%, and its specificity was $61 \%$. Its negative predictive value was $88 \%$, and its positive predictive value was $29 \%$. Patients living alone were 2.35 times more likely to be frail.

- $\quad$ Presence of aid at home

Patients with aid at home had a 12.32-fold risk of being frail compared to patients without aid.

The sensitivity of this item was $80 \%$, and its specificity was $89 \%$. Its negative predictive value was $95 \%$, and its positive predictive value was $64 \%$.

- Memory

"Memory impairment" had a sensitivity of $55 \%$ and a specificity of $71 \%$. Its negative predictive value was $87 \%$, and its positive predictive value was $31 \%$.

Patients responding positively to this element had a 2.34-fold risk of being frail.

- Polymedication

Patients responding positively to this element had a risk of being frail multiplied by 3.65 .

To identify frailty, the sensitivity of the " 5 or more therapeutic classes" element was $75 \%$, and the specificity was $62 \%$. Its negative predictive value was $91 \%$, and its positive predictive value was $33 \%$. 
Table 6. Pearson correlation matrix between Zulfiqar and SEGA elements and scores (see heatmap below).

\begin{tabular}{|c|c|c|c|c|c|c|c|c|c|c|c|c|c|}
\hline & Age & Provenance & Medications & Mood & $\begin{array}{l}\text { Perception of } \\
\text { health }\end{array}$ & $\begin{array}{c}\text { Fall } 6 \\
\text { Months }\end{array}$ & Nutrition & Sickenesses & AIVQ & Mobility & Continence & Meals & Cognition \\
\hline Weight loss & 0.00 & 0.05 & -0.11 & 0.16 & 0.06 & 0.21 & 0.90 & -0.03 & -0.07 & 0.11 & -0.01 & -0.02 & 0.06 \\
\hline $\begin{array}{l}\text { Monopodal } \\
\text { balance }\end{array}$ & 0.48 & 0.33 & 0.15 & 0.07 & 0.19 & 0.17 & -0.02 & 0.04 & 0.44 & 0.36 & 0.24 & 0.09 & 0.13 \\
\hline Live alone & 0.23 & 0.30 & 0.17 & 0.05 & 0.02 & 0.30 & 0.03 & 0.14 & 0.10 & 0.29 & 0.03 & -0.09 & -0.11 \\
\hline $\begin{array}{c}\text { Presence of } \\
\text { home helpers }\end{array}$ & 0.51 & 0.95 & 0.23 & -0.03 & 0.19 & 0.23 & 0.08 & 0.10 & 0.61 & 0.60 & 0.14 & -0.06 & 0.19 \\
\hline Memory loss & 0.20 & 0.16 & 0.07 & 0.06 & -0.02 & -0.11 & 0.02 & 0.02 & 0.42 & 0.06 & 0.18 & 0.14 & 0.71 \\
\hline
\end{tabular}

Table 7. Comparison of ZFS element scores between frail and non-frail patients.

\begin{tabular}{|c|c|c|c|}
\hline \multicolumn{4}{|c|}{ ZFS } \\
\hline Characteristics & Frail, $N=36$ & Not Frail, N = 66 & $p$-Value \\
\hline Weight loss & & & 0.2 \\
\hline No & $32(89 \%)$ & $64(97 \%)$ & \\
\hline Yes & $4(11 \%)$ & $2(3.0 \%)$ & \\
\hline Monopod support & & & $<0.001$ \\
\hline No & $5(14 \%)$ & $42(64 \%)$ & \\
\hline Yes & $31(86 \%)$ & $24(36 \%)$ & \\
\hline Live alone at home & & & $<0.001$ \\
\hline No & $10(28 \%)$ & $47(71 \%)$ & \\
\hline Yes & $26(72 \%)$ & $19(29 \%)$ & \\
\hline Presence of aid at home & & & $<0.001$ \\
\hline No & $14(39 \%)$ & $63(95 \%)$ & \\
\hline Yes & $22(61 \%)$ & $3(4.5 \%)$ & \\
\hline Memory loss & & & 0.007 \\
\hline No & $17(47 \%)$ & $50(76 \%)$ & \\
\hline Yes & $19(53 \%)$ & $16(24 \%)$ & \\
\hline No & $9(25 \%)$ & $47(71 \%)$ & \\
\hline Yes & $27(75 \%)$ & $19(29 \%)$ & \\
\hline
\end{tabular}


Table 8. Summary of all ZFS tool results compared to SEGA criteria.

\begin{tabular}{|c|c|c|c|c|c|c|c|c|}
\hline & & SEGA & & Se & $\mathrm{Sp}$ & PPV & NPV & $\mathbf{R R}$ \\
\hline Characteristics ZFS & Frail, $N=20$ & Not Frail, $N=82$ & $p$-Value & & & & & \\
\hline Weight loss & & & 0.013 & & & & & \\
\hline No & $16(80 \%)$ & $80(98 \%)$ & & $20 \%$ & $98 \%$ & $67 \%$ & $83 \%$ & 4.00 \\
\hline Yes & $4(20 \%)$ & $2(2.4 \%)$ & & & & & & \\
\hline Monopodal support & & & 0.004 & & & & & \\
\hline No & $3(15 \%)$ & $44(54 \%)$ & & $85 \%$ & $54 \%$ & $31 \%$ & $94 \%$ & 4.84 \\
\hline Yes & $17(85 \%)$ & $38(46 \%)$ & & & & & & \\
\hline No & $7(35 \%)$ & $50(61 \%)$ & & $65 \%$ & $61 \%$ & $29 \%$ & $88 \%$ & 2.35 \\
\hline Yes & $13(65 \%)$ & $32(39 \%)$ & & & & & & \\
\hline $\begin{array}{c}\text { Presence of aid at } \\
\text { home }\end{array}$ & & & $<0.001$ & & & & & \\
\hline No & $4(20 \%)$ & $73(89 \%)$ & & $80 \%$ & $89 \%$ & $64 \%$ & $95 \%$ & 12.32 \\
\hline Yes & $16(80 \%)$ & $9(11 \%)$ & & & & & & \\
\hline Memory loss & & & 0.056 & & & & & \\
\hline No & $9(45 \%)$ & $58(71 \%)$ & & $55 \%$ & $71 \%$ & $31 \%$ & $87 \%$ & 2.34 \\
\hline Therapeutic classes & & & 0.006 & & & & & \\
\hline $\mathrm{N}$ & $5(25 \%)$ & $51(62 \%)$ & & $75 \%$ & $62 \%$ & $33 \%$ & $91 \%$ & 3.65 \\
\hline $\mathrm{O}$ & $15(75 \%)$ & $31(38 \%)$ & & & & & & \\
\hline
\end{tabular}

Se: sensitivity; Sp: specificity; PPV: positive predictive value; NPV: negative predictive value. 
Finally, the area under the curve of the Zulfiqar Fragility Scale was 0.94116, as shown in Figure 1. As shown in Table 9, the significant cut-off in terms of sensitivity, specificity, $P P V$, and VPN was $\geq 3 / 6$.

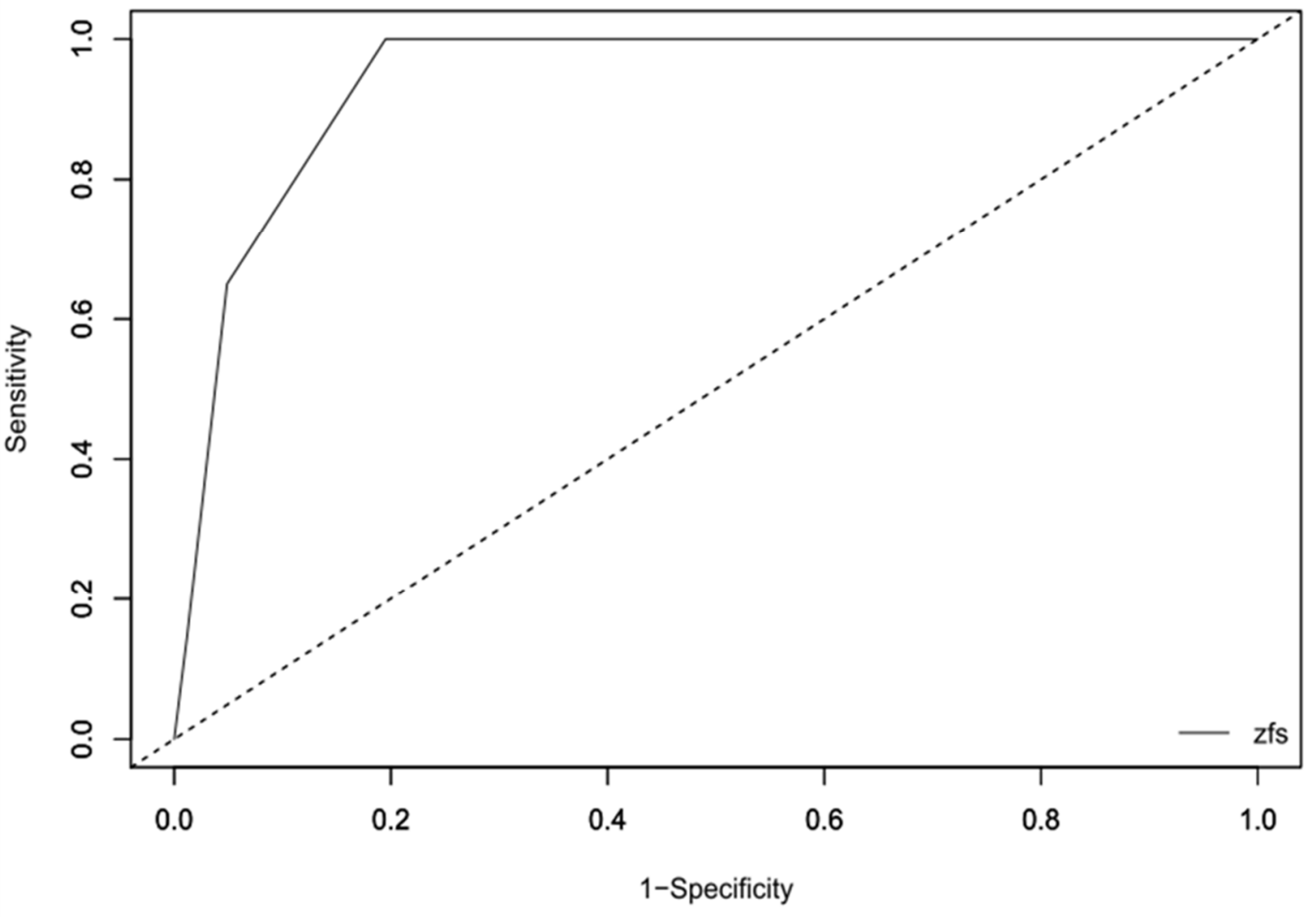

Figure 1. ROC curve of the Zulfiqar Frailty Scale.

Table 9. Interpretation thresholds for the ROC curve.

\begin{tabular}{cccccccc}
\hline Marker & Cutpoint & 1-Sp & Se & Sp & Youden & PPV & NPV \\
\hline ZFS & $>0$ & 1 & $100 \%$ & $0 \%$ & $0 \%$ & $19 \%$ & \\
ZFS & $>1$ & 0,8171 & $100 \%$ & $18 \%$ & $18 \%$ & $22 \%$ & $100 \%$ \\
ZFS & $>2$ & 0,6098 & $100 \%$ & $39 \%$ & $39 \%$ & $28 \%$ & $100 \%$ \\
ZFS & $>3$ & 0,1951 & $100 \%$ & $80 \%$ & $80 \%$ & $55 \%$ & $100 \%$ \\
ZFS & $>4$ & 0,0488 & $65 \%$ & $95 \%$ & $60 \%$ & $76 \%$ & $92 \%$ \\
ZFS & $>5$ & 0,0122 & $15 \%$ & $99 \%$ & $14 \%$ & $74 \%$ & $83 \%$ \\
\hline
\end{tabular}

Se: sensitivity; Sp: specificity; PPV: positive predictive value; NPV: negative predictive value.

\section{Discussion}

The challenge of screening for frailty in the elderly is growing with the current demographic changes, which will intensify in the years and decades to come. The major player in frailty screening is the general practitioner, the latter having responsibility for individual and community prevention, screening, coordination of care, and even monitoring [13].

The psychomedicosocial reflection that results from this fragility has given rise in recent years to various screening scores and scales, with the goal of managing this element within the elderly population. 
The current gold standard for screening frailty in elderly patients is the Fried Phenotypic Frailty Scale [1], recommended as a first-line of treatment by the American Geriatric Society and the Haute Autorité de Santé (HAS) [14]. However, the pitfall represented by the use of a dynamometer makes this screening tool difficult to use in general medicine. In addition, this scale is only interested in frailty in the sense of sarcopenia and neglects psychosocial components.

Kenneth Rockwood's Canadian teams conceptualized a frailty index appropriately named the Frailty Index [2,15]. Established according to a multidimensional clinical model of frailty, it is based on 70 dichotomous elements, taking into account physical elements (incontinence, cardiovascular pathology, etc.) as well as psychological and cognitive factors, and focusing on their repercussions on the activities of daily living (i.e., autonomy). This scale classifies elderly subjects into seven categories from "very robust" to "severely frail" including "in good health" or even "in good health with pathologies treated". It considers frailty as a cumulative variable where each deficit would worsen fragility, unlike the Fried scale. However, it remains poorly suited to outpatient medicine due to time constraints, with no less than 70 elements to be completed.

In this context, other scales have emerged, particularly a scale from the Seven-Point Research Program for the Integration of Autonomy Maintenance Services (PRISMA-7) which is a scale of seven simple, self-declared elements [16,17]. This questionnaire has a high level of precision in the identification of frailty among the elderly living in communities, but tends to over-screen for frailty. In fact, Clegg et al. showed that PRISMA 7 had high sensitivity but limited specificity as a simple instrument for identifying frailty. This means that there are many false-positive test results, which limit its diagnostic test accuracy [18].

The Gérontopôle de Toulouse (GFST) frailty screening tool consists of six closedanswer questions focusing on isolation, weight loss, asthenia, walking, and memory disorders. In addition, there is a subjective question for the general practitioner: "Does your patient seem fragile to you?" [6-8]. The main limitation of this tool remains the subjectivity of its elements. However, it is not intended to be a scale, but simply a screening tool, making it possible to detect subjects requiring care in a day hospital.

For our study, we used the SEGA (Short Emergency Geriatric Assessment) scale, initially developed by a Belgian research team (that of Pr Schoevaerdts) to allow for rapid and early identification of the geriatric profile of elderly people admitted to emergency rooms [3]. The SEGA tool was developed from the risk factors for functional decline as described in the literature, expert opinions, and data from the DecLIC (DecLine Investigation Cohort). It studied the factors of functional decline in the emergency environment for 600 patients over 70 years old $[3,4]$. At the end of this process, thirteen factors were selected and grouped together in part A of the modified SEGA scale, empirically weighted in three levels $(0,1$, and 2$)$. Part B of the grid groups together categories of information, established by the various professional experiences that can facilitate or, on the contrary, make it difficult to prepare for discharge from hospital. The grid was carried out in the emergency room by a doctor or an experienced nurse with the patient and their entourage with a relatively short completion time (less than ten minutes) and was based on the patient's situation fifteen days before their admission. The grid was neither a geriatric assessment nor a prognostic tool. It was, however, associated with certain indicators of geriatric fragility (increased length of stay, admission to geriatrics, hospital readmission within six months, mortality rates, etc.), thus enabling it to become, for each patient, a high-risk geriatric profile. It was then taken over by the RéGéCa Geriatrics Network (Champagne-Ardenne Geriatric Network) and the Reims University Hospital, after having been modified to adapt its terms and then applied to an outpatient population. In 2014, Dr. Drama's team from the Reims University Hospital validated psychometric part A of the grid on a cohort of 167 elderly subjects living at home [4]. Tardieu et al. conducted a prospective longitudinal multi-center cohort study, hospitalized in a short stay medical 
ward via emergency department: the SAFES group and showed poor convergent validity (Donini instrument, Rockwood instrument, and Winograd instrument) [5].

The latest scale, developed by Dr Zulfiqar, is a multi-faceted tool, taking into account the clinical, psychological, and social dimensions of the patient. In order for it to be suitable for general medicine, it needs to be, above all, simple, efficient, and quick to conduct. In addition, it needs an appropriate level of sensitivity as well as a high negative predictive value for its validity. This was shown in the princeps study [9]. A second study, comparing the performance of the so-called Zulfiqar frailty scale with the Fried scale, confirmed the results observed in the originator study. This study was accepted in the Belgian Journal of General Medicine SSMG (Scientific Society of General Medicine) and is in the process of being published [10].

With a sensitivity of $100 \%$, a negative predictive value of $100 \%$ and an area under the curve of 0.94, the Zulfiqar Scale showed a high level of performance in addition to relevance, since it correlates well with the SEGA scale. This study also showed, via the threshold analysis, that this scale detected the frailty of the elderly subject from the presence of three of the six elements.

Our study showed a different proportion on the frailty rate detected by the two scales. This can be explained by the non-measurement of the proportion of pre-frail subjects by the SEGA scale.

Regarding the objective of adapting to ambulatory medicine, this frailty scale seems to have several advantages. Indeed, it does not require prior training of caregivers, nor additional equipment such as a dynamometer (as is required for the Fried scale and can represent a financial impediment). The completion time was less than two minutes on average (in this study, it was an average $87 \mathrm{~s}$ ). Time can vary from four to ten minutes to receive a modified SEGA score [3,19-21], as also observed in our study. This difference in treatment time is not negligible since the average duration of a consultation in general medicine is $15-16 \mathrm{~min}$, or even more in the case of an elderly patient with multiple pathologies [22]. This can be a real advantage in the context of large-scale screening, especially during the quarterly prescription renewal consultation or during home visits.

Limitations: Our study sample remained small. To be validated for the purpose of studying its reproducibility, our tool must be tested in multiple general medicine practices, in urban and rural areas, and over a larger sample with many types of practitioners (doctors, nurses, physical therapists, occupational therapists). The prediction of pathological events (falls, hospitalization, and morbidity-mortality) was not studied in this research. This task will start soon.

\section{Conclusions}

The Zulfiqar Frailty Scale seems to be suitable for wide use in ambulatory medicine, whether in the office or at home, due to its simplicity and speed of execution. Ultimately, its reproducibility and its performance in predicting an unfavorable development under stress should be initiated and tested in the elderly. Further studies will be conducted in the coming months.

Funding: This research received no external funding.

Institutional Review Board Statement: The study was conducted according to the guidelines of the Declaration of Helsinki, and approved by the Internal Department Ethics Committee of University Hospital of Strasbourg and approved this paper for publication $\left(\mathrm{N}^{\circ} 18-10-20\right)$.

Informed Consent Statement: Informed consent was obtained from all subjects involved in the study. Written informed consent has been obtained from the patient(s) to publish this paper.

Data Availability Statement: The datasets used and/or analyzed during the current study are available from the corresponding author on reasonable request.

Conflicts of Interest: The authors declare no conflict of interest. 


\section{References}

1. $\quad$ Fried, L.P.; Tangen, C.M.; Walston, J.D.; Newman, A.B.; Hirsch, C.; Gottdiener, J.S.; Seeman, T.E.; Tracy, R.P.; Kop, W.J.; Burke, G.L.; et al. Frailty in Older Adults: Evidence for a Phenotype. J. Gerontol. Ser. A Boil. Sci. Med. Sci. 2001, 56, M146-M157. [CrossRef]

2. Rockwood, K.; Song, X.; MacKnight, C.; Bergman, H.; Hogan, D.B.; McDowell, I.; Mitnitski, A. A global clinical measure of fitness and frailty in elderly people. Can. Med. Assoc. J. 2005, 173, 489-495. [CrossRef] [PubMed]

3. Schoevaerdts, D.; Biettlot, S.; Malhomme, B. Identification précoce du profil gériatrique en salle d'urgences: Présentation de la grille SEGA. Rev. Geriatr. 2004, 29, 169.

4. Oubaya, N.; Mahmoudi, R.; Jolly, D.; Zulfiqar, A.A.; Quignard, E.; Cunin, C.; Nazeyrollas, P.; Novella, J.-L.; Dramé, M. Screening for frailty in elderly subjects living at home: Validation of the modified Short Emergency Geriatric Assessment (SEGAm) instrument. J. Nutr. Health Aging 2014, 18, 757-764. [CrossRef] [PubMed]

5. Tardieu, É.; Mahmoudi, R.; Novella, J.-L.; Oubaya, N.; Blanchard, F.; Jolly, D.; Dramé, M. External validation of the short emergency geriatric assessment (SEGA) instrument on the SAFES cohort. Geriatr. Psychol. Neuropsychiatr. Vieil. 2016, 14, 49-55. [CrossRef] [PubMed]

6. Subra, J.; Gillette-Guyonnet, S.; Cesari, M.; Oustric, S.; Vellas, B. Intégrer le concept de fragilité dans la pratique clinique: L'expérience du Géron-topôle à tra-vers la plateforme d'évaluation des fragilités et de prévention de la dépendance. Cah Année Gérontologique 2012, 4, 269-278. [CrossRef]

7. Subra, J.; Gillette-Guyonnet, S.; Cesari, M.; Oustric, S.; Vellas, B.; Platform The Platform Team. The integration of frailty into clinical practice: Preliminary results from the Gérontopôle. J. Nutr. Health Aging 2012, 16, 714-720. [CrossRef] [PubMed]

8. Vellas, B.; Balardy, L.; Gillette-Guyonnet, S.; Van Kan, G.A.; Ghisolfi-Marque, A.; Subra, J.; Bismuth, S.; Oustric, S.; Cesari, M. Looking for frailty in community-dwelling older persons: The Gerontopole Frailty Screening Tool (GFST). J. Nutr. Health Aging 2013, 17, 629-631. [CrossRef] [PubMed]

9. Zulfiqar, A.A. Creation of a New Frailty Scale in Primary Care: The Zulfiqar Frailty Scale (ZFS). Medicines 2021, 8, 19. [CrossRef] [PubMed]

10. Zulfiqar, A.A.; Suarez, J.; Andrès, E. Création d'une nouvelle échelle de fragilité en ambulatoire: Échelle de fragilité de Zulfiqar. SSMG. in press.

11. Sternberg, S.A.; Schwartz, A.W.; Karunananthan, S.; Bergman, H.; Clarfield, A.M. The Identification of Frailty: A Systematic Literature Review. J. Am. Geriatr. Soc. 2011, 59, 2129-2138. [CrossRef] [PubMed]

12. Kojima, G. Frailty as a predictor of disabilities among community-dwelling older people: A systematic review and me-ta-analysis. Disabil Rehabil. 2017, 39, 1897-1908. [CrossRef] [PubMed]

13. Compagnon, L.; Bail, P.; Huez, J.-F.; Stalnikiewicz, B.; Ghasarossian, C.; Zerbib, Y.; Piriou, C.; Ferrat, É.; Chartier, S.; le Breton, J.; et al. Définitions et descriptions des compétences en médecine générale. Exercer 2013, 108, 148-155.

14. HAS Comment Repérer la Fragilité en Soins Ambulatoires? Available online: https://prod-web.has-sante.fr/upload/docs/ application/pdf/2013-06/fiche_parcours_fragilite_vf.pdf (accessed on 27 October 2020).

15. Rockwood, K.; Stadnyk, K.; MacKnight, C.; McDowell, I.; Hébert, R.; Hogan, D. A brief clinical instrument to classify frailty in elderly people. Lancet 1999, 353, 205-206. [CrossRef]

16. Raîche, M.; Hébert, R.; Dubois, M.-F. PRISMA-7: A case-finding tool to identify older adults with moderate to severe disabilities. Arch. Gerontol. Geriatr. 2008, 47, 9-18. [CrossRef] [PubMed]

17. Hoogendijk, E.O.; van der Horst, H.E.; Deeg, D.J.H.; Frijters, D.H.M.; Prins, B.A.H.; Jansen, A.P.D.; Nijpels, G.; van Hout, H. The identification of frail older adults in primary care: Comparing the accuracy of five simple instruments. Age Ageing 2013, 42, 262-265. [CrossRef] [PubMed]

18. Clegg, A.; Rogers, L.; Young, J. Diagnostic test accuracy of simple instruments for identifying frailty in community-dwelling older people: A systematic review. Age Ageing 2014, 44, 148-152. [CrossRef] [PubMed]

19. Zulfiqar, A.A. Screening of frailty in the Emergency Unit: Myth or reality? Rev. Med. Liege 2018, 73, 206-210. [PubMed]

20. Martin-Kleisch, A.; Drame, M.; Zulfiqar, A.A. Feasibility of assessing frailty in general medicine patients aged over 65 . Rev. Epi-demiol. Sante. Publique 2019, 67, 169-174. [CrossRef] [PubMed]

21. Feck, E.; Zulfiqar, A.A. Screening of frailty in family practice by the modified SEGA grid. Rev. Med. Liege 2018, 73, 513-518. [PubMed]

22. Breuil-Genier, P.; Goffette, C. La durée des séances des médecins généralistes. In Études Résultats; DREES: Paris, France, 2006; $\mathrm{N}^{\circ} 481 ;$ pp. 1-8. 